\title{
Benefits of translanguaging and transculturation exchanges between international higher degree research students and English medium research supervisors
}

Minglin Li, School of Humanities, Languages and Social Sciences, Griffith University Beryl Exley, School of Education \& Professional Studies, Griffith University

\begin{abstract}
Discussions around internationalisation in Higher Degree Research (HDR) supervision have advocated a "deparochialising" (Lingard, 2006) of research education for international students via approaches that make use of students' existing language, culture and theoretical knowledge. Ideas include taking up reflexive and collaborative learning (Ryan, 2011) and HDR supervisors of international students being open to translanguaging (Li \& García, 2016) and transculturation practices (Choy, Singh \& Li, 2017). We explore interview data from international HDR students from language backgrounds other than English and some English speaking HDR supervisors working with international HDR students to document their assumptions about translanguaging and transculturation practices. The transcripts reveal these are regular practices for these participants. Both sets of participants agree that translanguaging and transculturation practices (i) enhance the specificity of the communication, (ii) promote the expertise of the HDR student, (iii) provide two-way learning, and (iv) feed into new knowledge generating practices. Translanguaging and transculturation practices are thus more than the reciprocal exchange of ideas; they are new forms of pedagogic processes whereby communicative work changes research processes, practices and systems of knowledge production, transfer, and acquisition that benefit both the HDR student and the HDR supervisor.
\end{abstract}

\section{Cross-cultural Higher Degree Research Supervision}

Given the burgeoning uptake of Higher Degree Research (HDR) students studying in a language and culture other than their own, it is prudent to focus on the pedagogic practices of this interaction. Many international HDR students seek to develop their understanding of global interrelatedness, connect to international research communities and contribute positively to these communities as well as their own (Choy, Singh \& Li, 2017). Research literature has already documented the challenges with cross-linguistic and cross-cultural HDR supervision. For example, in a multi-institutional semi-structured interview-based study with HDR students and supervisors who had experience in cross-cultural/cross-linguistic supervision, Winchester-Seeto et al. (2014) identified challenges including separation from the familiar, language and communication difficulties, and cultural differences in dealing with the hierarchy of the supervisor/student relationship.

From another viewpoint, Manathunga's (2017) Australian-based research illustrates "the negative consequences of adopting assimilationist approaches to doctoral pedagogies" ( $p$. 114). She calls on international HDR students to widen "what comes to count as knowledge globally" (p. 114) by integrating their own cultural and linguistic knowledge into their studies. She explains that "mutual respect, dialogic approaches to supervision and the recognition of the intellectual resources diverse students bring with them represent the core principles of empowering and effective intercultural supervision" (p. 115). She also argues for the take up of translanguaging and transculturation practices within HDR supervision so as to "develop more empowering intercultural communication and pedagogy" (p.114). In 
addition, Wisker and Robinson (2014) conceive of cultural difference as an opportunity to engage with "different learning behaviours, imperatives and concerns and different ways of constructing and expressing knowledge" (p. 19). These authors argue that when all parties appreciate cultural difference, learning from different perspectives is enabled.

In recent decades, discussions around internationalisation in HDR supervision have advocated a "deparochialising" (Lingard, 2006) of research education for international students and called for new approaches to supervision that harness the languages, culture and theoretical knowledge of HDR students via a process of reflexive and collaborative learning (Ryan, 2011). As Wisker and Robinson (2014) assert, global cultural flows can facilitate recognition of silenced voices of Indigenous, international and immigrant researchers and their topics, expressions, methodology and methods. Dooley, Exley and Poulus (2016), Manathunga (2011), and Singh (2009) have reported on the experiences of research teams whose members come from disparate linguistic, cultural and knowledge positions. Similarly, Exley, Davis and Dooley (2016) document their personal experiences of the need to make their individual cultural positions explicit. Davis, a strong and proud Australian Aboriginal man, teacher and researcher moves with ease between Indigenous and non-Indigenous worlds and world views. Exley and Dooley, however, are white, non-Indigenous teacher educators and researchers with long histories of teaching and researching in and for schools in communities marked by diversity and disadvantage. In their accounts, they acknowledge Davis' role in transmitting to them the principles of Indigenous research which includes "giving up the Western researcher-educator's illusion of the right to 'know all"' (p. 40). Exley and Dooley also document that they do not always fully participate in some yarning (community talking) sessions because it is sometimes culturally inappropriate to do so. In another case, Exley, Whatman and Singh (2018) recount the tension-ridden processes of negotiating Western educational research ethics policies and procedures and ways of knowing and being in Indigenous contexts. For example, Exley identifies the "hegemonic University Research Ethics policies and procedures, in particular their officious consent forms, sequencing dilemmas and the dilemma with confidentiality and acknowledgement" ( $p$. 535). Whatman confirmed the "unpredictableness of qualitative data collection and that issues of ethics can be a protracted process" when undertaken in a culturally appropriate way (p. 535).

Other research literature explores Western HDR supervisors working with international HDR students who have English as an Additional Language (EAL) and non-Western backgrounds (see, for example, Choy, Singh \& Li, 2017; Manathunga, 2011, 2013; Singh, 2009; Singh \& Chen, 2012). In this chapter, we explore interview data from international HDR candidates with Asian backgrounds whose first language is not English and some English speaking HDR supervisors working within a large city-based Australian university. All participants selfidentified as engaging in translanguaging and transculturation practices. We hone in on four productive outcomes for the international HDR students and the HDR supervisors. Before we do so, the next section overviews the definitions of translanguaging and transculturation used in this chapter.

\section{Translanguaging and transculturation practices in education}

Translanguaging is a linguistic practice used in multilingual situations, as well as a pedagogical practice used in educational settings. The term translanguaging was coined by Cen Williams (1994), popularized through Baker's Foundations of Bilingual Education and Bilingualism (2001/2011), and extended by researchers in diverse linguistic and cultural 
contexts (see, e.g., Li \& García, 2016). Translanguaging offers a unique way of conceptualizing bilingualism as "a new and transformed linguistic system rather than the addition of two" languages (Li \& García, 2016, p. 5). Translanguaging emphasizes that the bilingual speaker is not two monolinguals in one (Grosjean, 1982), but that at its very core, the psycholinguistic system of a bilingual speaker is different to that of monolingual speakers (de Bot, Lowie \& Verspoor, 2007). According to Velasco and García (2014), the languages of bilingual speakers are not separate linguistic systems, but one linguistic system - an integrated linguistic repertoire from which bilingual speakers choose the language or choose to switch between the languages to communicate with others.

Research undertaken by García and Kano (2014) documents students and teachers engaging in complex discursive practices that cycle between the language practices of each. When activated, these "complex and fluid discursive practices" span a range of multimodal texts, such as those produced through "reading, writing, listening, discussing, taking notes, writing reports and essays, and taking exams" (García, 2014, p. 74). Creese and Blackledge (2010) refer to these practices as translanguaging, a flexible bilingualism, used as instructional strategies that also "make links for classroom participants between the social, cultural, community, and linguistic domains of their lives" (p. 112).

Translanguaging practices serve to sustain existing language practices, develop new language practices and facilitate the communication of appropriate knowledge, thus giving voice to "new sociopolitical realities" (García \& Kano, 2014, p. 261). In examining the translanguaging pedagogies used in language classrooms, Creese and Blackledge (2010) stated:

Both languages are needed simultaneously to convey the information ... each language is used to convey a different informational message, but it is in the bilingualism of the text that the full message is conveyed. (p. 108)

García (2009) also refers to "multiple discursive practices in which bilinguals engage in order to make sense of their bilingual worlds" (p. 45, italics in original). Baker (2001/2011) highlights the multimodality of translanguaging as well, noting that when topics are read or heard in one language, and then written or discussed in another language, the subject matter has to be "digested" (p. 289). Translanguaging also implicates an individual's capacity to "think, reflect, and extend their inner speech" (García \& Kleifgen, 2010, p. 63) and to explore the representation of values, identities and relationships ( $\mathrm{Li}, 2011)$.

Li (2011) refers to translanguaging space as "a space for the act of translanguaging as well as a space created through translanguaging" (p. 1223). He asserts that translanguaging space has its own "transformative power" (p. 1223). It is not a space where different identities, values and practices simply co-exist, but a space where the process of "cultural translation" (Bhabha, 1994) between traditions takes place with the possibility of generating new identities, values and practices. Translanguaging spaces are a special form of pedagogy with their own cognitive processes and rules for interaction and interpretation situated within unique socio-historical dimensions (Li, 2011).

An increasing number of HDR students are writing in multilingual contexts, and the varieties of linguistic and cultural resources brought by multilingual students to their academic writing has been recognised by a growing number of researchers (see, for example, Canagarajah, 2011; Kaufhold, 2018; Mazak, 2017; Singh, 2009). Research has acknowledged the 
contribution translanguaging makes to students' academic learning (see, for example, Lewis, Jones, \& Baker, 2013), and academic writing (see e.g., Canagarajah, 2011; Kaufhold, 2018; Velasco \& García, 2014). Li (2011) proposes that translanguaging advances creativity via choosing "between following and flouting the rules and norms of behaviour, including the use of language" and "pushing and breaking the boundaries between the old and the new, the conventional and the original, and the acceptable and the challenging" (p. 1223). Li (2011) also proposes that translanguaging advances criticality via bringing insights of various cultural, social and linguistic phenomena to question and problematize received wisdom and to express a position. Processes of translanguaging, however, are not without points of tension due to the ranges of ideologies, policies and practices being brought into the encounter ( $\mathrm{Li}, 2011)$.

We use transculturation to refer to the use of cultural concepts from international HDR students' home countries in their research while studying in Western countries. The term transculturation was coined in 1940 by the Cuban anthropologist Fernando Ortiz in opposition of the term acculturation that had been coined by anthropologists in the United States in 1936 (Taylor, 1991). Taylor (1991) considers transculturation as the phenomenon of emerging and converging of cultures, the transformative process involved in the acquisition of foreign cultural material - "the loss or displacement of a society's culture due to the acquisition or imposition of foreign material, and the fusion of the indigenous and the foreign to create a new, original cultural product" (p. 91). Transculturation thus includes the displacement of one's preceding culture as an incoming culture is being absorbed to create a uniquely new cultural phenomena. The theory of transculturation "delineates the process by which symbols, discourse, and ideology are transformed as one culture changes through the imposition or adoption of another, and examines the historic and socio-political forces that produce local meanings" (Taylor, 1991, p. 92). Transculturation is thus a political process as the consciousness of one society's histories and manifestations comes into contact with the histories and manifestations from other societies. Pratt (1991) explains how members of marginalized groups do not unthinkingly imitate or reproduce the language of the dominant culture, but to varying extents choose what is appropriated and how it gets used. Zamel (1997) emphasizes the nature of transculturation which "assumes and celebrates the selective, generative, and inventive nature of linguistic and cultural adaptation and thus reflects precisely how languages and cultures develop and change - infused, invigorated, and challenged by variation and innovation" (p. 350). Therefore, she encourages the transculturation model that recognizes this process of adaptation as dynamic, involving both active engagement and resistance.

Singh, Manathunga, Bunda and Qi (2016) argue for a theoretical model of transcultural coresearch practice in research education. Singh et al. (2016) point to the necessity of the transcultural approach given the contradictory processes produced by globalization that "promote the movement of people and ideas across geographical and epistemological boundaries yet continue to reinforce the dominance of White, Western knowledge production" (p. 54). The Indian-Australian, Irish-Australian, Aboriginal and Chinese researchers on this team grappled with cultural differences as they undertook their research work. Working together, they examined how "renegade knowledge" can be included in doctoral supervision using a process of intellectual contestation, dissensus and dialogue (Singh et al., 2016, p. 59). In their transcultural co-research, they strove to nurture a dynamic meaning-making through self-reflexive learning based on each author's intellectual contributions and (trans)cultural dispositions. Grounding their transcultural co-research in "a reconceptualization of intellectual power in a globalized and technology-driven world" they 
argue that "intellectual power today can no longer simply take the point of advantage on knowledge hierarchies, but should be actualized through mutual learning, intellectual responsibility and a transcultural research disposition" (Singh et al., 2016, p. 60). They regard this transcultural practice as a departure from one-way mentoring to a pedagogic process that mobilizes the expertise of all team members. Encouraged by Singh et al.'s (2016) conceptualization, Choy, Singh and Li (2017) call into question the need for the prefix "trans", stating that cultures are neither fixed, static nor tightly bounded and transcultural practice involves incorporation of cultural knowledge and theories from other intellectual traditions based on the assumption of an equality of intelligences.

In this chapter, we explore the assumptions of international HDR students from language backgrounds other than English and their English speaking research supervisors as they use translanguaging and transculturation practices. To contribute to the emerging research theory in internationalising HDR education, we draw on international HDR students and HDR supervisor recounts where Western and native languages, and cultural knowledge and theories have been synthesised.

\section{Research Methods}

Using a two-phase multi-method research design, our study explores how multilingual international HDR students from Asian linguistic and cultural backgrounds (hereafter EAL HDR students) and English-speaking research supervisors (hereafter HDR supervisors) recount their use of translanguaging and transculturation for positive gains.

Upon receipt of ethical approval from the University's Human Research Ethics Committee, HDR coordinators in this large city-based teaching and research-intensive university in Australia were contacted to assist with sending email invitations and the requisite Information Sheet and Consent Form to prospective participants who had completed their HDR confirmation (usually at the end of the first full year of HDR study). We also emailed invitation letters, and the requisite Information Sheet and Consent Form to HDR supervisors who have supervised and/or are supervising EAL HDR students. All potential participants were asked to engage in two tasks: an individual interview of up to 60 minutes, and confirmation of the written transcript of the individual interview.

Seven EAL HDR students from Asian linguistic and cultural backgrounds and ten HDR supervisors from a range of disciplinary fields agreed to participate in this research. The participants confirmed that the EAL HDR students were studying with Australian universities as the students wanted to learn from the West and because of a perceived benefit of acquiring Western knowledge. All participating HDR supervisors reported that they encouraged their EAL HDR students to utilize, where appropriate in their dissertation, the language, cultural concepts and philosophical ideas from their home countries on the proviso that the dissertation continued to meet the examination requirements. In all cases except one, the EAL HDR students who attended the interviews could not be matched to a HDR supervisor participant. In almost all cases, the HDR supervisors were recounting experiences with EAL HDR students who had already graduated.

In the first phase of the study, semi-structured interviews were carried out by the first author in places selected by the participants. These semi-structured interviews proved to be useful for gathering in-depth information about participants' accounts of their experiences and assumptions. In addition, these semi-structured interviews allowed for good interpretive 
validity (Gay \& Airasian, 2003; Johnson \& Turner, 2003). The list of semi-structured interview questions were based around demographic data, research topic, use of translanguaging and transculturation practice, and reasons for using or not using translanguaging and transculturation practices. These semi-structured interview questions were derived from our knowledge of the research literature and were supplemented with probing questions during the interview (Robson, 2002). The audio recording of the interviews were then transcribed by a professional transcribing service. In the second phase of the study, the interview transcripts were sent to participants for content review and additional comments. No participants requested any changes or provided any further comments.

A thematic approach was adopted to analyse the edited transcripts to derive a list of assumptions when using translanguaging and transculturation practices in HDR supervision. After reading the transcripts several times, the first author identified some major themes which were then coded using both descriptive and interpretive codes (Miles \& Huberman, 1994). These codes were then utilized to retrieve details from the transcripts about the benefits of translanguaging and transculturation practices for further analysis, presentation and discussion.

In the next section of this chapter, we present the four reported benefits of translanguaging and transculturation practices between EAL HDR students and their English medium supervisors during HDR supervision at an Australian university. In what follows, we draw on data provided by a range of participants. When presenting the participants' recounts, false starts and long pauses were removed to ensure a more fluent reading experience. Italics are used to show verbatim data transcripts and ellipses show where data were removed because of a topic shift. When speech was unclear, the transcription is shown in square brackets. When data included details that could potentially identify the interview participant or another person, the words were removed and replaced with [[removed]].

\section{Reported Benefits of Translanguaging and Transculturation Practices in HDR Supervision}

\section{Enhances the specificity of communication}

The seven EAL HDR students and the ten HDR supervisors reported that translanguaging and transculturation practices enhanced the specificity of the communication between the EAL HDR students and the HDR supervisors. Participants reported using specific words from EAL HDR students' first language (L1) when finding an equivalent word in English proved difficult or impossible. Taking up L1 words enhanced the presentation and interpretation of the meaning, particularly when the point of discussion referred to cultural implications, local literature, or when data were generated and collected in the L1 of the EAL HDR student. One of the EAL HDR students explained using L1 words when presenting data:

So in my thesis I tend to use the way how ... the participants express themselves. So I would put directly or literally in their own languages, in their own words, and then I would explain in English what that means. For example, there is a specific term, one of (the participants) say, this kind of curriculum design or planning is called "Liang Zhang Pi”. (Student 1) 
Student 1 explained that Liang Zhang Pi has two layers of meaning, or two different/separate systems like that, and justified that using Liang Zhang P $i$ instead of a translated English term conveyed underlying meanings associated with the cultural background. Student 1 also explained that the HDR supervisor encouraged the use of translanguaging and transculturation practices.

Supervisor 1 recalled that some of her EAL HDR students definitely had to use their own language because they've had to take primary source materials written in [[removed]] or [[removed]] and translate them into English for the purpose of the thesis. Supervisor 1 emphasized that the EAL HDR students had to bring their own understandings of their culture to their research work when commenting on the cultural, social and political contexts of their home countries. Supervisor 1 commented on the value of EAL HDR students' translanguaging and transculturation practices, saying that:

It adds a lot of depth to their thesis so they're able to combine their own language, their own culture, with what they learn here, in order to, I think, hopefully, produce very high quality, in-depth theses. And I think it adds value to the whole process, that they come in ... with that different perspective. (Supervisor 1)

\section{Promotes the expertise of the EAL HDR student}

In separate interviews, Supervisors 1 and 2 explained that they had to encourage their EAL HDR students to take on an expert role via translanguaging and transculturation practices. Excerpts from the interview data provided by these supervisors are as follows:

I have had to say a few times, no, you're the expert, you tell me, because ... I don't have expertise in [[removed]] regulation. I can help with writing a good thesis, but ... you are the expert, you have to be. (Supervisor 1)

I think that in many ways the students are more confident if they are talking, not only more confident, I think they feel that they have more to contribute if they're trying to make those relationships work between what their culture's thinking and saying and what other cultures are thinking and saying. (Supervisor 2)

Supervisor 3 described having to work with the EAL HDR students to shift their thinking about being afraid of displeasing their supervisors by not following their supervisor's Western research orientation, instead taking the initiative to introduce transculturation practices. Supervisor 3 identified that, under the consistent encouragement of their HDR supervisors, the EAL HDR students were becoming familiar with taking some responsibility for their own $\mathrm{PhD}$ and in the process becoming independent researchers. Supervisor 1 recalled that her Asian students were quite pleased and a bit surprised but happy as they recognised their growing status as experts.

Supervisor 1 provided dialogue about the constant points of discussion centred on the EAL HDR students being encouraged to shift their previously held cultural position of the supervisor as the expert, to the new position of the EAL HDR student as the expert on the topic of their dissertation.

It's great to be respected but you have to tell them though it's your thesis, you have to take control and ownership of it and you make decisions about [it], and I will guide 
you and we can talk it through but at the end of the day, you have to decide. ... it is important sometimes for these students to make sure they feel empowered to take control of their own thesis and the direction because they know more than I do about, really, what they need to say in that thesis. ... I think they liked the idea that I said, no, you're the expert, you tell me. Or, I'll constantly reiterate, I'll give feedback and I'll say, look, I would do this way and I would change the structure and include this here, but will that be right, you know, and I'll keep asking them for their input and I think they like that. I think they've come to like it. ... I guess, as well as empowering them, giving them a sense of responsibility for their own learning (Supervisor 1).

\section{Encourages two-way learning}

Interview data also explored the realisation that HDR supervisors sometimes lacked certain content knowledge, or sometimes pretended to lack certain content knowledge that seemed crucial to the research study. Supervisor 3 described themselves as ignorant about culture of another kind, or in some cases pretending to be ignorant about culture of another kind, therefore relying on the EAL HDR student to fill the knowledge gap. Supervisor 3 homed in on the difficulty of the task besetting the EAL HDR student whilst also discussing the benefits of two-way learning.

When you come from one kind of culture to another kind of culture and the value systems or the scholarly structures are different, there is adjustment that has to be made to produce a thesis in that culture and, I mean, it was a hard thing. It must be a terribly hard thing. ... But I don't think it's a bad thing to do; I think it's a great thing to do but it does involve a different level of learning and it also involves working with a supervisor in such a way that you can kind of educate them, and this is another role of the student. I hate to admit it but I'm ignorant. When I get a student from Malaysia or Iran or Iraq or from Africa, those students come with their own set of expert knowledges but they don't have my expert knowledge, and I don't have theirs, so when they come to me with a way of thinking about a topic, I have to try and make sense of it and they have to try and help me to make sense of it by teaching me what they're thinking about. (Supervisor 3)

Supervisor 1 also indicated that transculturation practices added valued to the supervisor's knowledge base.

So, before they started, I probably didn't know very much but we've had interesting discussions about it, so it's been more about developing an understanding....It's me learning from them. Yeah, very much. So, they brought that knowledge and as I said, it adds value and depth to their thesis and they explain it to me. (Supervisor 1)

Student 2 overtly labelled the transculturation practices as two ways learning, explaining the simultaneous benefit to the HDR supervisor and the EAL HDR student.

So it is like two-ways learning because that surprised them in what occurred in the workplace in [[removed]] and then they feed in with me what happened in the workplace in Australia. So, it's two-ways learning; they learn about what happen in my culture and then learn about what happened in the [Australian] culture and I use the differences and similarity in order to better explain or clarify the results I use. (Student 2). 
Following on from the theme of two-way learning, Student 3 explained how the HDR supervisor's interest in the HDR study motivated the EAL HDR student to continue their studies.

I think I became more motivated in trying to get the message across and so even though it was a part of my reading for my thesis but after such a discussion, I was trying to read more about how people wrote about [[removed]] culture in those situations. Yeah, so it's like more reading for me but I was trying because I was more motivated by my supervisor's interest in that part of the results so I just read more and tried to improve my writing so that I can actually get the message across. Yes, so I think it's helped to improve my writing, also my reading. (Student 3 )

\section{New knowledge generating practices}

A point borne out of Supervisor 3's interview data was the realisation that both the EAL HDR student and the HDR supervisor used translanguaging and transculturation practices to generate new knowledge. In talking about an EAL HDR student's English language proficiency, Supervisor 3 homed in on the need to develop a common language for the purpose of speaking in scholarly terms and establishing intellectual commonality. Supervisor 3 acknowledged the complexity of these discussions, not only because of the translanguaging but also because of the transculturation practices. Supervisor 3 recounted that it was quite hard to tease out a way to approach and understand that complexity. After a number of meetings with plenty of explanations and discussions, Supervisor 3 would search for more relevant materials. Although it took a lot of time, by the end of the project, a much richer cross cultural analysis was undertaken.

Supervisor 3 recounted an EAL HDR student's use of translanguaging and transculturation practices in a dissertation that explored published editions of folktales from a particular Asian country. Supervisor 3 commented:

So one of the things I found challenging was to understand how the stories had layers of meaning. So they weren't just stories in which things happen, you know, a fisherman looks at the moon and then a magic spirit comes out of the moon and comes down to earth and something changes, you know, it wasn't just that. For me, there had to be a symbolic value but I found it very difficult to understand what that symbolic value was and I think my student found it hard to articulate that for me because for her it was intuitive. She felt she'd learnt it from childhood and she understood it, but how to express it in English to me was extremely difficult. ... So it was quite elusive or slippery kind of thing to get hold of, as you say, the implied meaning or the underlying meaning of a set of things that happen. (Supervisor 3)

Supervisor 3 reported that the strategy agreed upon with the EAL HDR student was to present some of the folk stories in L1 with English translation and an appendix as needed. According to Supervisor 3, this approach involved not only linguistic translation but cultural translation also. Supervisor 3 acknowledged that translation is a stressful and an extremely hard thing, but that the process brings rewards because it involves a different level of learning. 
Supervisor 1 provided an example of how translanguaging and transculturation practices generated a major change to the theoretical framework for the student's dissertation. The supervisor and students went to a conference together and attended a paper presentation discussing cultural comparison, something with potential for the student's thesis. Supervisor 1 recounted that that framework:

really explained what's happening in [[removed]]. So it actually allows you to culturally position ... and actually figuratively draw this and explain ... the weakness we are finding are real weaknesses. They are not weaknesses in what you should do, but they won't work until you do these things. (Supervisor 1)

Supervisor 1 emphasized the importance of learning and knowing about EAL candidates' background cultural knowledge, saying to supervise that you have to actually understand it and in this case really understanding where [[removed]] Higher Education fits in the world as well, and what are the implications. Given the uniqueness of each individual research setting in Asian countries, it is highly likely that a theoretical framework developed in Western countries is not applicable in Asian countries. For this reason, Supervisor 1 asserted that:

So we have to also be careful that as Australian supervisors we don't try and impose Australian cultural values on an Asian setting where the research is being done. We have to acknowledge where it is. So I mean I've found out so much that I didn't know, and it's interesting, ... and it's sort of developing ... mutual respect and making sure students know that they are becoming the expert, and we work with them to help them look at an issue, make sure they're doing it rigorously, ... [choosing] the framework for what they are doing. (Supervisor 1)

Student 3 detailed how they and the supervisors have both enriched their cultural repertoire through translanguaging and transculturation practice and how together they have developed the appropriate research instrument for interviews carried out in Student 3's home country. Student 3 was thinking about using a survey designed in another country and used widely internationally, but as Student 3 explained, there is no cultural evaluation of the scale whether the scale using Asian culture is different from that used in European or Western culture. Student 3 identified some dimensions that were consistent across cultural groups, but also a dimension with a very high level of uncertainty when compared across cultural groups. After extensive analysis, Student 3 chose to use a cultural concept to explain the results.

\section{Concluding Discussion}

As Manathunga (2013) asserts, "the pressure towards assimilation to Western research norms and ways of knowing remains very strong in Western universities" (p. 78), including universities in Australia. Analysis that highlights the benefits of translanguaging and transculturation practices is therefore important. Our analysis shows that our participants made four positive assumptions about translanguaging and transculturation practices. The first positive outcome of translanguaging and transculturation practices within HDR supervision was enhancement of the specificity of communication, an outcome reported in Velasco and García's earlier work (2014). The second positive outcome of translanguaging and transculturation practices was the elevation of the EAL HDR student as an expert. Singh (2009) has long advocated that HDR supervisors must recognize and acknowledge their own cross-cultural ignorance and in doing so acknowledge the expertise of the EAL HDR student. Manathunga (2011) supports this view and points out that "supervisors may have to accept 
that there is a great deal they do not or cannot know" (p. 368). Singh (2009) claims that when HDR supervisors acknowledge their own ignorance, the reward is that they have an "incentive for learning" (p. 187). Thus ignorance, leads to the third positive outcome of translanguaging and transculturation practices, that of two-way learning that value-adds to the HDR supervisor's knowledge base. The fourth positive outcome of translanguaging and transculturation practices within HDR supervision is new knowledge generation practices. Manathunga (2007) identifies this as moments of "creativity", where "culturally diverse students may carefully select those parts of Western knowledge that they find useful and seek to blend them with their own knowledge and ways of thinking" (pp. 97-98).

Thus, when translanguaging and transculturation practices are permitted into the HDR supervision encounter, they have the potential to bring with them their own "transformative power" (Li, 2011, p. 1223) that benefits both the EAL HDR student and the HDR supervisor. The translanguaging and transculturation practices that specify communication, position the EAL HDR student as the expert, provide for two-way learning and produce new knowledge generating practices create the space for creativity in HDR supervision. In this way, the data reported here suggest that translanguaging and transculturation practices take HDR supervision beyond its mundane pedagogies of teaching students about using theoretical concepts, research methods and the analysis of findings. As a point of difference, our findings indicate that HDR supervision that adopts translanguaging and transculturation practices has the potential to build connections between the intellectual resources of EAL HDR students and their disparate worldviews to inform the knowledge base of the HDR supervisor in unanticipated and unexpected ways. This compilation of data thus suggests that translanguaging and transculturation practices are more than the reciprocal exchange of ideas; they are pedagogic and curriculum processes where communicative work leads to change in research processes, practices and systems of knowledge production, transfer and acquisition that benefit both the EAL HDR student and the HDR supervisor.

We, however, do not finish our discussion here. It would be remiss of us to not return to the broader discussion already mentioned earlier in this chapter, that whereby participating HDR supervisors asserted the proviso that the dissertation continued to meet the Western examination requirements. Despite some reported benefits of translanguaging and transculturation practices, there is no escaping the ongoing impact of Western imperialism on EAL HDR students' linguistic, ideological, cultural, and technological form. Yet again, as Merriam and Kim (2008) point out, the EAL HDR students still need to give way to Western norms as they finalise their dissertation for examination; Western knowledge seems to be forsaking nothing in the processes outlined. In this sense, the call for further research into translanguaging and transculturation practices in international HDR supervision seems timely.

\section{References}

Baker, C. (2001/2011). Foundations of bilingual education and bilingualism ( $\left.3^{\text {rd }} \mathrm{ed}.\right)$. Clevedon: Multilingual Matters.

Bhabha, H. (1994). The Location of Culture. Routledge: London.

Canagarajah, S. (2011). Codemeshing in academic writing: Identifying teachable strategies of translanguaging. The Modern Language Journal, 95(3), 40-417.

Choy, S., Singh, P., \& Li, M. (2017). Trans-cultural, trans-language practices: Potentialities for Rethinking Doctoral Education Pedagogies. Education Sciences, 7(19). doi:10.3390/educsci7010019 
Creese, A. \& Blackledge, A. (2010). Translanguaging in the bilingual classroom: A pedagogy for learning and teaching? Modern Language Journal, 94(1), 103-115.

de Bot, K., Lowie, W., \& Verspoor, M. (2007). A dynamic systems theory approach to second language acquisition. Bilingualism Language and Cognition, 10(1), 7-21.

Dooley, K., Exley, B., \& Poulus, D. (2016). Research on critical EFL literacies: an illustrative analysis of some college level programs in Taiwan. English Teaching \& Learning, 40(4), 39-64.

Exley, B., Davis, J., \& Dooley, K. (2016). Empirical reference points for Bernstein's model of pedagogic rights: recontextualising the reconciliation agenda to Australian schooling. In P. Vitale \& B. Exley (Eds.), Pedagogic Rights \& Democratic Education: Bernsteinian explorations of curriculum, pedagogy \& assessment (pp. 3346). London: Routledge.

Exley, B., Whatman, S., \& Singh, P. (2018). Postcolonial, Decolonial Research Dilemmas: Fieldwork in Australian Indigenous Contexts. Qualitative Research, 18(5), 526-537.

García, O. (2009). Bilingual education in the 21st century: A global perspective. Malden: Wiley/Blackwell.

García, O. (2014). U.S. Spanish and Education: Global and Local Intersections. Language Policy, Politics, and Diversity in Education: Review of Research in Education, (38)1, 58-80.

Garcia, O. \& Kano, N. (2014). Translanguaging as process and pedagogy: Developing the English writing of Japanese students in the US. In J. Conteh \& G. Meier (Eds.), The Multilingual Turn in Languages Education: Opportunities and Challenges (pp. 258277). Bristol, UK: Multilingual Matters.

García, O., \& Kleifgen, J. A. (2010). Educating emergent bilinguals: Policies, programs, and practices for English language learners. New York, NY: Teachers College Press.

Gay, L. R., \& Airasian, P. (2003). Educational Research: Competencies for analysis and applications $\left(7^{\text {th }}\right.$ ed.). Upper Saddle River, New Jersey: Merrill-Prentice Hall.

Grosjean, F. (1982). Life with Two Languages: An introduction to bilingualism. Cambridge, MA: Harvard University Press.

Johnson, B., \& Turner, L. (2003). Data collection strategies in mixed methods research. In A. Tashakkori, \& C. Teddlie (Eds.), Handbook of Mixed Methods in Social and Behavioral Research (pp. 297-319). Thousand Oaks, CA: Sage.

Kaufhold, K. (2018). Creating translanguaging spaces in students' academic writing practices. Linguistics and Education, 45(2018), 1-9.

Lewis, G., Jones, B., \& Baker, C. (2013). 100 bilingual lessons: Distributing two languages in classrooms. In C. Abello-Contesse, P. Chandler, M. López-Jiménez, M. Torreblanca-López \& R. Chacón-Beltrán (Eds.), Bilingualism and Multilingualism in School Settings (pp. 107-135). Bristol: Multilingual Matters.

Li, Wei (2011). Moment analysis and translanguaging space: Discursive construction of identities by multilingual Chinese youth in Britain. Journal of Pragmatics, 43, 12221235.

Li, Wei \& García, O. (2016). From researching translanguaging to translanguaging research. In K. King, Y. Lai \& S. May (Eds.), Research methods in language and education. Encyclopedia of Language and Education ( $3^{\text {rd }}$ ed.) (pp. 1-14). Springer, Cham. DOI 10.1007/978-3-319-02329-8_16-1.

Lingard, B. (2006). Globalisation, the research imagination and deparochialising the study of education. Globalisation, Societies and Education, 4(1), 287-302.

Manathunga, C. (2007). Intercultural postgraduate supervision: Ethnographic journeys of identity and power. In D. Palfreyman \& D. McBride. (Eds.), Learning and Teaching across Cultures in Higher Education (pp. 93-113). New York: Palgrave Macmillan. 
Manathunga, C. (2011). Moments of transculturation and assimilation: Post-colonial explorations of supervision and culture. Innovations in Education \& Teaching International, 48(4), 367-376.

Manathunga, C. (2013). Culture as a place of thought: Supervising diverse candidates. In A. Engels-Schwarzpaul \& M. Peters. (Eds.), Of Other Thoughts: Non-traditional Ways to the Doctorate: A guidebook for candidates and supervisor (pp. 67-82). Rotterdam: Sense Publishers.

Manathunga, C. (2017). Intercultural doctoral supervision: The centrality of place, time and other forms of knowledge. Arts and Humanities in Higher Education, 16(1), 113-124.

Mazak, C. (2017). Introduction: Theorizing translanguaging practices in higher education. In C. Mazak \& K. Carroll (Eds.), Translanguaging in higher education: Beyond monolingual ideologies (pp. 1-28). Bristol: Multilingual Matters.

Merriam S., \& Kim, Y. S. (2008). Non-Western perspectives on learning and knowing. New Directions for Adult and Continuing Education, 119, 71-81.

Miles, M. B., \& Huberman, A. M. (1994). Qualitative data analysis: An expanded sourcebook $\left(2^{\text {nd }}\right.$ ed.). Thousand Oaks, CA: Sage.

Pratt, M. L. (1991). Arts of the contact zone. Profession, 91, 33-40.

Robson, C. (2002). Real world research: A resource for social scientists and practitionerresearchers. Oxford, UK; Madden, Mass.: Blackwell Publishers.

Ryan, J. (2011). Teaching and learning for international students: towards a transcultural approach. Teachers and Teaching, 17(6), 631-648, DOI: 10.1080/13540602.2011.625138

Singh, M. (2009). Using Chinese knowledge in internationalising research education: Jacques Rancière, an ignorant supervisor and doctoral students from China. Globalisation, Societies and Education, 7(2), 185-201.

Singh, M., \& Chen, X. (2012). Ignorance and pedagogies of intellectual equality: Internationalising Australian HDR education programs and pedagogies through engaging Chinese theoretical tools. In A. Lee \& S. Danby (Eds.), Reshaping HDR Education: Changing Programs and Pedagogies (pp. 187-203). London: Routledge.

Singh, M., Manathunga, C., Bunda, T., \& Qi, J. (2016). Mobilising Indigenous and nonWestern theoretic-linguistic knowledge in HDR education. Knowledge Cultures, 4(1), 54-68.

Taylor, D. (1991). Transculturating transculturation. Performing Arts Journal, 13(2), 90-104.

Velasco, P. \& García, O. (2014). Translanguaging and the writing of bilingual learners. Bilingual Research Journal, 37, 6-23.

Williams, C. (1994). Arfarniad o ddulliau dysgu ac addysgu yng nghyd-destun addysg uwchradd ddwyieithog [Evaluation of teaching and learning methods in the context of bilingual secondary education]. (Unpublished $\mathrm{PhD}$ thesis). University of Wales, Bangor, UK.

Winchester-Seeto, T., Homewood, J., Thogersen, J., Jacenyik-Trawoger, C., Manathunga, C., Reid, A., \& Holbrook, A. (2014). Doctoral supervision in a cross-cultural context: issues affecting supervisors and candidates. Higher Education Research \& Development, 33(3), 610-626.

Wisker, G., \& Robinson, G. (2014). Examiner practices and culturally inflected doctoral theses. Discourse, 35, 190-205.

Zamel, V. (1997). Toward a model of transculturation. TESOL Quarterly, 31(2), 341-352.

Author Details 
Dr Minglin Li is a Senior Lecturer in TESOL/Educational Linguistics in the School of Humanities, Languages and Social Science at Griffith University in Australia. Her research is in the area of Educational Linguistics with a particular focus on English language education policy and planning for Chinese schools where English is taught and learned as a foreign language (EFL). She explores how EFL teachers are actively involved in EFL education policy enactment in their teaching practice and how their practices impact on student learning. She also investigates factors influencing effective EFL teaching and learning in China at the school and tertiary level. Her recent work examines learners' dictionaries in order to assist EFL learners to maximize their learning. Minglin Li has a strong interest in Higher Degree Research (HDR) student supervision, exploring HDR curriculum and transcultural and trans-language practice in Higher Degree Research education.

Professor Beryl Exley specialises in English Curriculum and Literacies Education within the School of Education and Professional Studies at Griffith University, Queensland, Australia. Her $\mathrm{PhD}$ examined English language teaching in cross-cultural contexts from the viewpoint of offshore English teachers from Australia and the United Kingdom and from Indonesian language institution managers. Her research work applies a socio-cultural lens to examine the inherent features of language and literacy curricula, pedagogy and assessment in school and tertiary contexts, both in face-to-face and social media interactions. She also explores new pedagogical applications of system functional linguistics in early years, primary and secondary schooling contexts so that students are better resourced to enact a pedagogy of language inquiry for reading/viewing and writing/composing multimodal texts. She is interested in language and literacy as matters of social-justice for students and their teachers and how different processes of curricula, pedagogy and assessment provide access to disparate possibilities. 